\title{
Introducing Dairy: A Transdisciplinary Journal to Advance Understanding of Dairy Nutrition, Health and Productivity, Welfare and Well-Being as Well as Milk Synthesis-Composition and Health Effects of Its Products
}

\author{
Burim N. Ametaj \\ Department of Agricultural, Food and Nutritional Science, University of Alberta, Edmonton, AB T6G 2P5, \\ Canada; bametaj@ualberta.ca
}

Received: 21 June 2018; Accepted: 6 July 2018; Published: 9 July 2018

\section{Introducing a New Transdisciplinary Journal}

Milk is an excellent food source for both young animals and humans. It contains essential nutrients for both growth and maintenance. Milk is produced by dairy animals for different lengths of time immediately after parturition. Moreover, milk is produced by various dairy animals including cows, goats, sheep, buffalos, camels, yak, and other less studied species. The science of studying milk and dairy products, and the management of dairy farms, is known as dairy science. Animal health is very important for healthy milk and products. Milk alterations, occurring during mastitis, including pro-inflammatory cytokines, amino acids, lipids, carbohydrates, acylcarnitines, phosphatidylcholines, sphingomyelins, and minerals, are triggering new research looking into whether these changes in milk composition affect the health of young animals.

Therefore, it is with great pleasure that we launch this new journal called Dairy that will support publication of all research activities related to those issues. It should be noted that the scope of Dairy is greater than animal health, milk quality, and composition. Currently, a major paradigm switch is happening in biological sciences including dairy science and dairy animal health. We are moving from the mainstream philosophy of science, known as reductionism, to the new philosophy of science recognized as systems biology. We also are experiencing a boom in research activities that were unthinkable a decade ago, including research that utilizes 'omics' approaches like genomics, transcriptomics, proteomics, metabolomics, epigenetics, and bioinformatics. Moreover, advances in instrumentation, including various mass spectrometry instruments of all kinds, have helped dairy science rise to new heights, and advancement in instrumentation related to dairy is welcomed. We are living in interesting times, because the older complex issues that could not be solved by the reductionist approach are being tackled from the systems biology point of view that looks at interactions of multiple components in a system and at the non-linearity of the effects. All research activities that involve the utilization of systems biology approaches and 'omics' sciences are welcome to be published at Dairy.

Automation in dairy milking including robotic milking and the numerous measurements they offer (recording of milk yield and recording and monitoring of milk components) to dairy producers, as well as various software that further improve the management of dairy facilities, are also very interesting areas that warrant further research. Precision dairy farming including early detection of disease through monitoring biomarkers, development of new preventive intervention strategies including oral vaccines, and probiotics, and searching for new 'green' alternatives to anti-microbials, which aim to maximize animal performance are welcome to be published at Dairy. All research related to the monitoring of animal activity, lying and rumination behavior, milk conductivity indicators, and 
heat detection, as well as the monitoring of well-fare and well-being of animals are other areas of great interest for Dairy.

It should be noted that our progress in dairy sciences has been related to our progress in the research activities of the respective era. For instance, a rapid progress in genetics and artificial insemination in the 1940s was associated with improved breeding and selection of sires and dams with higher milk yield capacity. As an example, currently, there are dairy farms producing, as an average, 13,000-14,000 L/year and also a record-holding cow that produces up to 75,000 pounds of milk per year $(33,750 \mathrm{~L} /$ year) or $110 \mathrm{~L} / \mathrm{d}$. The same can be said for other dairy species, including dairy sheep producing $500 \mathrm{~L}$ of milk per year or dairy goats Saanen producing $\sim 3000 \mathrm{~L}$ of milk per year, that have increased milk yields over the last decades. The feeding of dairy animals has been improved with rations formulated to contain all the necessary nutrients to support very high milk production. However, it seems like we have not done the same with regards to the selection of animals for resistance to diseases. Moreover, the more milk yield has increased per dairy animal the more we are taking those animals away from their natural feeding habits, which obviously consist of grazing. This also has been associated with an increased incidence rate of feeding-related diseases like rumen acidosis or lameness and endotoxemia.

The transition period is associated with high incidence of multiple diseases and it is obvious that we are facing difficulty in fully understanding and preventing complex diseases including reproductive tract infections and infertility, mastitis, laminitis, milk fever, ketosis, and retained placenta without mentioning the more complex ones like downer cow or downer ewes, pregnancy toxemia, fatty liver, viral, and infectious diseases. These cause the dairy industry heavy losses that in dairy cows reach up to $30-40 \%$ of the entire herd.

It is obvious that from a dominantly single scientist approach to health or other complex issues of dairy animals, we need to be switching to a team or group approach from various layers including genomics, epigenetics, transcriptomics, proteomics, metabolomics, bioinformatics, nutrigenomics, and even mathematical approaches. These technologies would be very helpful to be used for better understanding the potential association of high milk yields with high incidence of diseases and suppressed immunity, commonly observed around parturition. The reductionist approach that we have used during the last few decades has been very successful in producing new knowledge and new hypotheses in the dairy sciences. Additionally, the reductionist philosophy has been an excellent methodological approach to simple problems like bacterial infections or broken bones. However, it should be accepted that the reductionist approach has encouraged the confirmation of scientists by working alone to solve one single issue in science and has discouraged collaborative research. Besides, the reductionist approach is failing us with regards to uncovering the real causes of complex diseases and also in developing new preventive or treatment strategies. Therefore, this new journal will encourage and support all collaborative research efforts and approaches to dairy science issues and will welcome all those types of researches with high priority. We should have in mind that both reductionist and systems biology approaches will co-exist side by side in biological sciences including dairy science and we also welcome all research efforts related to solving issues of various degrees of complexity.

A new area of research is microbiota of the gastrointestinal tract, reproductive tract, and mammary gland and their effects on health and diseases. There are reports connecting the alteration of bacterial communities in different body parts and the health of humans and animals. More research is warranted with regards to the role of microbiomes on the health of dairy. The effect of microbial biofilms established in various mucosal tissues and their effect on health of dairy animals is also of great interest. Of note is the pioneering work related to the utilization of probiotics for the improvement of health of dairy. New research will be strongly supported by Dairy. Full articles or short communications in this area of research are welcome to be published.

Milk and milk products play an essential role in the human diet throughout our lives, given the wide range of nutrients present in its composition. The proteins contain all the essential amino acids 
necessary to satisfy our nutritional needs. In addition, their digestion in the gastrointestinal tract generates bioactive peptides with numerous beneficial effects on human health. Calcium and many other essential minerals are of greatest interest because of their involvement in important physiological functions and due to their high bioavailability. Research on milk lipids, especially saturated fatty acids, and lactose are welcomed. Recent meta-analytical studies have shown that lipids play important functions in every single cell of the human and animal body and presence of lipids in the diet at moderate amounts is essential for health. Lactose intolerance also is known to affect certain groups of people; however, lactose-free milk has been available to those groups of people and certainly more research is warranted in this area of dairy research. Of great interest are the recent advances related to the paradigm shift of dietary saturated fats. This acquires great relevance in the case of research on the effect of consumption of regular milk and dairy products and the absence of evidence of risk of cardiovascular disease likely as a result of the presence of numerous bioactive lipid components, and especially the presence of short chain fatty acids.

Additionally, Dairy will consider, with great interest, research related to milk contamination by toxicants of all sorts, whether pesticides or insecticides, to heavy metals or other industry related toxicants that might enter human food chain through milk consumption in contaminated areas. Contamination of grains of all sorts and other feed materials from fungus or other contaminants and their potential hazardous effects on young dairy animals and humans are welcome to be submitted.

Finally, I am very excited that Dairy has a brilliant team of very experienced dairy scientists, as part of its Editorial Board, and among the best scientists in all areas of dairy science. We all are excited to start this new journal and welcome your new research. We are very much committed to provide you an extremely fair review process and a speedy publication. As part of our commitment to fairness, we are providing a double-blind peer review process, which means that both the reviewer and the author identities are concealed from each other. We strongly believe that this type of reviewing process will give you, the authors, an objective evaluation of your research work.

\section{Aims}

Dairy is an international, peer-reviewed open access forum for studies related to the advances in dairy science. It publishes reviews, regular research papers and short communications. Our aim is to encourage scientists to publish their experimental and theoretical results in as much detail as possible. There is no restriction on the length of the papers. The full experimental details must be provided so that the results can be reproduced. There are, in addition, unique features of this journal:

i Manuscripts regarding research proposals and research ideas will be particularly welcomed;

ii Electronic files or software regarding the full details of the calculation and experimental procedure, if unable to be published in a normal way, can be deposited as supplementary material;

iii We also accept manuscripts communicating to a broader audience with regard to research projects financed with public funds.

\section{Scope}

The Scope of Dairy includes the following:

- $\quad$ Milk and milk products

- Processing and technology

$\circ \quad$ Engineering

$\circ \quad$ Ingredients

- Physical and chemical properties

- Functional and nutritional properties

- Sensory and consumer preference

- Safety and quality 


$\begin{array}{ll}\circ & \text { Novel foods } \\ \circ & \text { Dairy neutraceuticals } \\ \circ & \text { Dairy products and human health } \\ \circ & \text { Saturated fats } \\ \circ & \text { Lactose intolerance } \\ \circ & \text { A1 and A2 beta-casein and health } \\ \circ & \text { HACCP }\end{array}$

- Dairy animal nutrition
- Nutrients intake
- Feed science
- Digestion
- Herd and pasture
- Milk production and composition
- Grains
$\circ \quad$ Silages

- Dairy animal welfare
$\circ \quad$ Housing
- Animal behavior

- Dairy animal health

$\begin{array}{ll}\circ & \text { Infertility } \\ \circ & \text { Mastitis } \\ \circ & \text { Lameness } \\ \circ & \text { Milk fever } \\ \circ & \text { Ruminal acidosis } \\ \circ & \text { Immunity } \\ \circ & \text { Periparturient diseases } \\ \circ & \text { Disease treatment and prevention } \\ \circ & \text { Biomarkers } \\ \circ & \text { Wellbeing and welfare } \\ \circ & \text { Alternatives to anti-microbials } \\ \circ & \text { Heat stress }\end{array}$

- $\quad$ Systems biology
- Genomics
- Transcriptomics
- Proteomics
- Metabolomics
- Mathematical modeling
- Bioinformatics

- Farm management
- Sustainable farming
- Green gas emission 


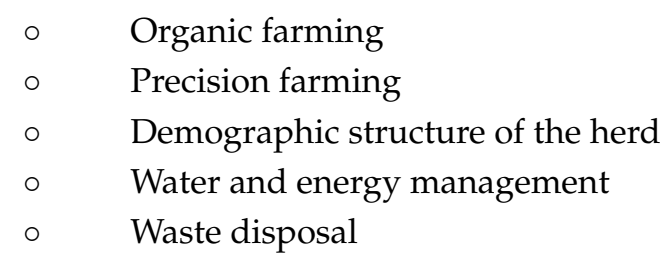

- Microbiota
- Pathogens
- Microbiology
- Probiotics
- Bacterial biofilms
- Bacteria contribution to disease

- Other

$\begin{array}{cl}\circ & \text { Labeling } \\ \circ & \text { Environment and ecology } \\ \circ & \text { Marketing and economics } \\ \circ & \text { Legislation and regulation } \\ \circ & \text { Agricultural policy }\end{array}$

\section{New Paradigms}

Dairy will support the presentation of new paradigms with regards to complex issues like periparturient diseases, the biological efficiency and the environmental impact of dairy animals, as well as dairy products and human health. It should be noted that the list of new paradigms includes many more areas of dairy research and they are all welcome to be presented to this journal. The reason for this new section of Dairy is that there are a lot of dogmas that have been introduced over the years that have lost their legacy and need to be revisited and replaced with new ideas and concepts so that we can make advances to all areas of dairy science. This journal will strongly support the publication of new paradigms without prejudice or obstacles. We also will strongly support the advancement of ideas and the new knowledge generated by 'omics' sciences and systems biology approaches.

\section{Conclusions}

In closing, on behalf of the Editorial Board, I welcome you to your new forum for sharing your science research, dairy animal health studies, dairy reviews, new hypotheses and paradigms, all your 'omics', and systems biology research activities and many more.

Acknowledgments: I would like to acknowledge the contribution of the following Editorial Board members to this editorial including (in alphabetical order), Pierluigi Carboni, Sven Dänicke, Hilton Deeth, Javier Fontecha, Alessandro Nardone, and Carlos A. F. Oliviera.

(C) 2018 by the author. Licensee MDPI, Basel, Switzerland. This article is an open access article distributed under the terms and conditions of the Creative Commons Attribution (CC BY) license (http://creativecommons.org/licenses/by/4.0/). 